Article

\title{
Microalgae Isolation and Selection for Prospective Biodiesel Production
}

\section{Van Thang Duong, Yan Li, Ekaterina Nowak and Peer M. Schenk *}

Algae Biotechnology Laboratory, School of Agriculture and Food Sciences, The University of Queensland, Brisbane 4072, Australia; E-Mails: van.duong@uqconnect.edu.au (V.T.D.); y.li12@uq.edu.au (Y.L.); k.nowak@uq.edu.au (E.N.)

* Author to whom correspondence should be addressed; E-Mail: p.schenk@uq.edu.au; Tel.: +61-7-3365-8817; Fax: +61-7-3365-1699.

Received: 5 April 2012; in revised form: 1 June 2012 / Accepted: 14 June 2012 /

Published: 15 June 2012

\begin{abstract}
Biodiesel production from microalgae is being widely developed at different scales as a potential source of renewable energy with both economic and environmental benefits. Although many microalgae species have been identified and isolated for lipid production, there is currently no consensus as to which species provide the highest productivity. Different species are expected to function best at different aquatic, geographical and climatic conditions. In addition, other value-added products are now being considered for commercial production which necessitates the selection of the most capable algae strains suitable for multiple-product algae biorefineries. Here we present and review practical issues of several simple and robust methods for microalgae isolation and selection for traits that maybe most relevant for commercial biodiesel production. A combination of conventional and modern techniques is likely to be the most efficient route from isolation to large-scale cultivation.
\end{abstract}

Keywords: algaculture; biodiesel; microalgae; lipid; fatty acids; transesterification; triacylglycerides 


\section{Introduction}

Microalgae have been considered for biodiesel production, based on their ability to grow rapidly and to accumulate large amounts of storage lipids, primarily in the form of triacylglycerides (TAG). Microalgae are a group of mostly photoautotrophic microorganisms that includes both prokaryotic and eukaryotic species. These organisms can photosynthetically convert $\mathrm{CO}_{2}$ and minerals to biomass, but some species also grow heterotrophically. Prokaryotic microalgae are cyanobacteria (blue-green algae) and eukaryotic microalgae include the nine phyla Glaucophyta, Chlorophyta, Chlorarachniophyta, Euglenophyta, Rhodophyta, Cryptophyta, Heterokontophyta, Haptophyta and Dinophyta. To date, about $2 / 3$ of 50,000 species have been identified and are kept in collection by various algal research institutes [1]. For example, the largest collection at present is the Collection of Freshwater Algae at the University of Coimbra, Portugal, maintaining about 4000 strains and 1000 species of algae; the Culture Collection of Algae of the Göttingen University, Germany harbors 2213 strains and 1273 species of both freshwater and marine algae; the Culture Collection of Algae in the University of Texas, USA, maintains 2300 strains of freshwater species; the National Institute for Environmental Studies in Japan is keeping 2150 strains with about 700 species of freshwater and marine algae [2]; the Australian National Algae Culture Collection (ANACC) maintains about 1000 strains of microalgae which were mostly isolated from Australian waters [3]. Although algae collections are maintained for many purposes (e.g., for pharmaceutical, food, energy and industrial products), only a few hundred strains have been investigated for chemical content and very few are cultivated in industrial quantities. To date, although there is mounting interest to develop microalgal biodiesel production, the cost for microalgal biomass production is currently much higher than from other energy crops [4]. Thus, selection of an energy and cost-efficient production model could play a very important role in achieving competitive biodiesel production. This includes the selection of high lipid-producing algae, suitable farming locations, efficient cultivation and harvesting methods and oil extraction procedures. Here, we focus on the first step, the selection of suitable high lipid-accumulating microalgae strains, a process that can be compared with the early domestication of current crop plants. In alignment with this purpose, this review aims to present a practical guide to several simple and robust methods for microalgae isolation and selection for traits that maybe most relevant for commercial biodiesel production.

\section{Advanced Microalgae Biodiesel Production}

The developments in the biodiesel industry have progressed dramatically in recent years. Developed countries have set priorities on biodiesel fuels for the transport and mechanical industry and established a Biodiesel Board for policy making and development. The production of biodiesel in the EU has been increasing from 1.9 million tons in 2004 to 3.2 million tons in 2005 and to 4.9 million tons in 2006 [5]. In 2011, biodiesel production rose to 22.117 million tones as reported by the European Biodiesel Board (EBB); the leading biodiesel producing countries in the area include Germany, France and Spain [6]. The United States is also developing biodiesel applications in many different industries. According to the US National Biodiesel Board, biodiesel production increased from 0.016 million tons in 1999 to 0.787 million tons in 2004 [7]. Production and sales were estimated to have tripled from 2004 to 2005 and to have reached 21.73 million tons of fuel in 2008 and more 
than 31.5 million tons in 2011, as reported by The U.S. National Biodiesel Board (TUSNBB) [8]. To date, research on biodiesel production from microalgae is enthusiastically attempted globally.

In comparison with other sources (e.g., animal fat, oleaginous grain crops and oil palm), there are remarkable advantages of biodiesel from microalgae as an alternative energy source for the future. Advantages include the following: (i) areal growth rate and oil productivity of microalgae per unit of land use are much higher than those of other biofuel crops; (ii) algae grow in a wide range of environments. Fresh, brackish and saline waters are ideal environments for growth of different algae species. Even in municipal and other types of wastewater, algae grow well by using inorganic $\left(\mathrm{NH}_{4}{ }^{+}, \mathrm{NO}_{3}{ }^{-}, \mathrm{PO}_{4}{ }^{3-}\right)$ as well as organic sources of nutrients [9]; (iii) microalgae absorb $\mathrm{CO}_{2}$ photosynthetically and convert it into chemical energy and biomass. The removal of $\mathrm{CO}_{2}$ from the atmosphere (and possibly industrial flue gases) may play an important role in global warming mitigation by replacing fossil fuel emissions [9,10]. Producing 100 tonnes of algal biomass fixes roughly 183 tonnes of carbon dioxide from the atmosphere [4]; (iv) microalgae can provide raw materials for different types of fuels such as biodiesel, ethanol, hydrogen and/or methane which are rapidly biodegradable and may perform more efficiently than fossil fuels [11]; (v) products extracted from algal biomass can be used as sources for organic fertilizers or high value products, such as omega-3 fatty acids, sterols, carotenoids and other pigments and antioxidants, and could be amenable to a zero waste biorefinery concept [9]. Therefore, microalgae have been regarded as possibly the only route to sustainable displacement of high proportions of fossil oil consumption.

\section{Biodiesel Conversion from Microalgae}

The process of isolation and selection of algae strains needs to consider the requirements of algal oil suitable for biodiesel production. Algal lipids occur in cells predominantly as either polar lipids (mostly in membranes) or lipid bodies, typically in the form of triacylglycerides. The latter are accumulated in large amounts during photosynthesis as a mechanism to endure adverse environmental conditions. Polar lipids usually contain polyunsaturated fatty acids which are long-chained, but have good fluidity properties. TAG in lipid storage bodies typically contain mostly saturated fatty acids which have a high energy contents, but, depending on the fatty acid profile of the algae strain, may lack fluidity under cold conditions. Provided the algal oil is low enough in moisture and free fatty acids, biodiesel is typically produced from TAG with methanol using base-catalyzed transesterification [12]. Most current feedstock for biodiesel production is based on plant oils produced from oil palm, soybean, cottonseed and canola, recycled cooking greases or animal fats from beef tallow or pork lard [13]. According to Fukuda, transesterification using base catalysts is 4,000 times faster than using acid catalysts [14]. Some common base catalysts used by industry are sodium hydroxide and potassium hydroxide. Use of lipase enzymes as a catalyst is efficient, however their use is limited because of the high costs [14]. The best temperature for the reaction is typically $60{ }^{\circ} \mathrm{C}$ under normal atmospheric pressure. If the temperature is higher, methanol will boil, lowering the efficiency [14]. During the transesterification process, saponification reactions can occur, forming soap. Thus, oil and alcohol must be dried. Finally, biodiesel is recovered by washing rapidly with water to remove glycerol and methanol [4]. The high potential of oil production from microalgae has attracted several companies to commercialize biodiesel from microalgae (e.g., MBD Energy Pty and Muradel 
Pty Ltd in Australia). Basically, algal biodiesel is produced after algae cultivation and harvesting, followed by oil extraction and its conversion by transesterification. Principally, microalgal oil can be directly used as fuel feedstock, based on the conventional process of biodiesel production, provided the fatty acid profile is favorable. But even algal oils with a high degree of saturation (e.g., similar as tallow) can be considered as a drop-in fuel (e.g., for B20 blends). In addition, scientists are also focusing on the conversion to higher value products. For example, thermal cracking is used for decomposition of triglycerides into hydrocarbons such as alkans, alkenes, and aromatic compounds $[15,16]$.

\section{Isolation and Selection Criteria for Microalgae with Potential for Biodiesel Production}

\subsection{Sampling and Isolation of Pure Cultures}

Microalgae grow in most of the natural environments including water, rocks and soil, but interestingly also grow on and in other organisms. Their main habitats are freshwater, brackish and marine ecosystems. Microalgae can be found and collected not only in general aquatic ecosystems such as lakes, rivers and the oceans, but also in extreme environments such as volcanic waters and salt waters. Local microalgae species should be collected because it can be expected that they have a competitive advantage under the local geographical, climatic and ecological conditions. Our experience has shown that water and sediment samples from aquatic environments that undergo fluctuating and/or occasional adverse conditions provide a higher chance of isolating high lipid accumulating microalgae. Most likely these conditions would favor robust and opportunistic (fast-growing) algae with superior survival skills (e.g., by accumulation of storage lipids). Examples of these environments are tidal rock pools, estuaries and rivers.

Isolation is a necessary process to obtain pure cultures and presents the first step towards the selection of microalgae strains with potential for biodiesel production. Traditional isolation techniques include the use of a micropipette for isolation under a microscope or cell dilution followed by cultivation in liquid media or agar plates. Single cell isolation, based on traditional methods from the original sample is time-consuming and requires sterilized cultivation media and equipment, but the result of this elaborate process is always a pure culture that is usually easily identifiable. Another approach in the laboratory includes the enrichment of some microalgae strains by adding nutrients for algal growth. The most important nutrient sources for algal growth are nitrogen and phosphate. Some particular algae species may require trace minerals for their growth (e.g., silicon for diatoms). Soil water extract is an excellent source of nutrients for algae growth at this stage because this medium is easy to produce and satisfies nutrient intake of many algae strains. Although automatic isolation techniques have offered some advantages towards traditional methods (see below), single cell isolation by a micropipette (e.g., a glass capillary) is still a very effective method that can be used for a wide range of samples and is very cost-effective. An automated single cell isolation method that has been developed and widely used for cell sorting is flow cytometry [17]. This technique has been successfully used for microalgae cell sorting from water with many different algae strains [18], primarily based on properties of chlorophyll autofluorescence (CAF) and green autofluorescence (GAF) to distinguish algae species such as diatoms, dinoflagellates or prokaryotic phytoplankton. 
Unlike for many agricultural crops, a targeted selection and domestication of microalgae strains is still in its infancy, while technology to economically grow microalgae with high lipid content is still being developed [4]. Each microalgae strain requires careful selection and optimization in order to increase lipid productivity with the aim to provide a cropping system with improved biofuel production and performance properties [19]. Each micro-environment may provide algae strains with very different properties. As opposed to only manipulating a few individual cultured algae strains in the laboratory for high lipid productivity, a more efficient and useful strategy to identify oleaginous microalgae would be an in-depth and systematic investigation of a whole taxonomic group of microalgae over a wide geographical and ecological distribution [20]. By correlating this with algal oil contents and optimal environmental growth conditions, a predictive tool for selecting optimal microalgae strains for biofuel production maybe developed. A bioinformatics approach could assist with the discovery of new algae isolates capable of biodiesel production and their phylogenetic grouping may suggest that potentially many more species have this ability. Typically, the steps involved in obtaining data for phylogenetic analysis include primers design (Table 1), DNA and/or RNA extraction, PCR amplification, denaturizing gradient gel electrophoresis and/or sequencing.

Table 1. Examples of $18 \mathrm{~S}$ rDNA primers for the identification of microalgae by sequencing.

\begin{tabular}{|c|c|c|c|c|c|}
\hline $\begin{array}{l}\text { Primer } \\
\text { name }\end{array}$ & Forward (5'-3') & $\begin{array}{l}\text { Primer } \\
\text { name }\end{array}$ & Reverse (5'-3') & Species & References \\
\hline TH18S5' & GGTAACGAATTGTTAG & TH18S3' & GTCGGCATAGTTTATG & $\begin{array}{l}\text { Thalassiosira } \\
\text { pseudonana }\end{array}$ & [21] \\
\hline P45 & $\begin{array}{l}\text { ACCTGGTTGATCCTGC } \\
\text { CAGT } \\
\text { GTCAGAGGTGAAATTC } \\
\text { TTGGATTTA }\end{array}$ & P47 & $\begin{array}{l}\text { TCTCAGGCTCCCTCTC } \\
\text { CGGA } \\
\text { AGGGCAGGGACGTAA } \\
\text { TCAACG }\end{array}$ & $\begin{array}{l}\text { Chlorella vulgaris } \\
\text { Dunaliella salina }\end{array}$ & $\begin{array}{l}{[22]} \\
{[23]}\end{array}$ \\
\hline SS5 & $\begin{array}{l}\text { GGTGATCCTGCCAGTA } \\
\text { GTCATATGCTTG } \\
\text { GAAGTCGTAACAAGG } \\
\text { TTTCC } \\
\\
\text { CCAACCTGGTTGATCC } \\
\text { TGCCAGTA }\end{array}$ & SS3 & $\begin{array}{l}\text { GATCCTTCCGCAGGTT } \\
\text { CACCTACGGAAACC } \\
\text { TCCTGGTTAGTTTCTT } \\
\text { TTCC } \\
\\
\text { CCTTGTTACGACTTCA } \\
\text { CСTTCСTCT }\end{array}$ & $\begin{array}{l}\text { Navicula } \mathrm{sp} . \\
\text { Chlorella } \mathrm{sp} . \\
\text { Chlamydomonas } \\
\text { coccoides } \\
\text { Tetraselmis suecica } \\
\text { Nannochloris } \\
\text { atomus } \\
\text { Nannochloropsis sp. }\end{array}$ & $\begin{array}{l}{[24]} \\
{[25]}\end{array}$ \\
\hline
\end{tabular}

In 2010, seven microalgae genomes had been completed [27] and current efforts to obtain many other microalgal genome sequences will enhance gene-based biofuel feedstock optimization studies (e.g., by metabolic engineering). The accumulation of storage lipid precursors and the discovery of genes associated with their biosynthesis and metabolism is a promising topic for investigation. For example, genes encoding key enzymes involved in biosynthesis and catabolism of fatty acids/TAG and their regulation are currently not well understood (for a review of the lipid biosynthesis pathway in microalgae see Schuhmann et al. [28]). By providing insight into the mechanisms underpinning the relevant metabolic processes, efforts can be made to identify molecular markers for selection or to genetically manipulate microalgae strains to enhance the production of feedstock for commercial 
microalgal biofuels. To date, genetic engineering approaches have been successfully used to improve biofuel phenotypes only in Chlamydomonas reinhardtii, Nannochloropsis gaditana and Phaeodactylum tricornutum [29].

\subsection{Lipid Determination}

Lipid determination in qualitative and quantitative analysis is crucial for identification of suitable strains for biodiesel production. Conventional methods such as solvent extraction or gravimetric methods have been used by Bligh and Dyer [30]. Separation and profiling of lipid components require elaborate techniques in order to satisfy criteria of biodiesel quality and includes thin layer chromatography (TLC), gas chromatography-mass spectroscopy (GC/MS) and/or high pressure liquid chromatography (HPLC) [31]. These methods are time-consuming for lipid extraction and analysis, especially for a large number of samples. Thus, a rapid screening for lipid content in organisms or cells is necessary and important for high-throughput screening. Nile red (9-diethylamino-5-benzo[ $\alpha]$ phenoxazinone), a lipophilic stain, maybe used for this purpose. It was first synthesized by Thorpe in 1907 by boiling Nile blue with sulfuric acid, and in the same year, Smith reported the use of Nile red for detecting lipids in human cells [32]. The application of Nile red for lipid staining in microorganisms such as bacteria, yeasts and microalgae is now a common practice that allows a rapid qualitative determination of lipids in cells (Figure 1) [33].

Figure 1. Cylindrotheca closterium and Scenedesmus sp. after Nile red staining under bright light $(\mathbf{A}, \mathbf{C})$ or fluorescence microscopy under blue light $(\mathbf{B}, \mathbf{D})$, respectively. Yellow dots show lipid bodies containing triacylglycerides; orange color indicates polar lipids and red shows autofluorescence from chlorophyll. Samples were obtained from a coastal rock pool (A,B); and a freshwater creek $(\mathbf{C}, \mathbf{D})$ in South East Queensland, Australia.

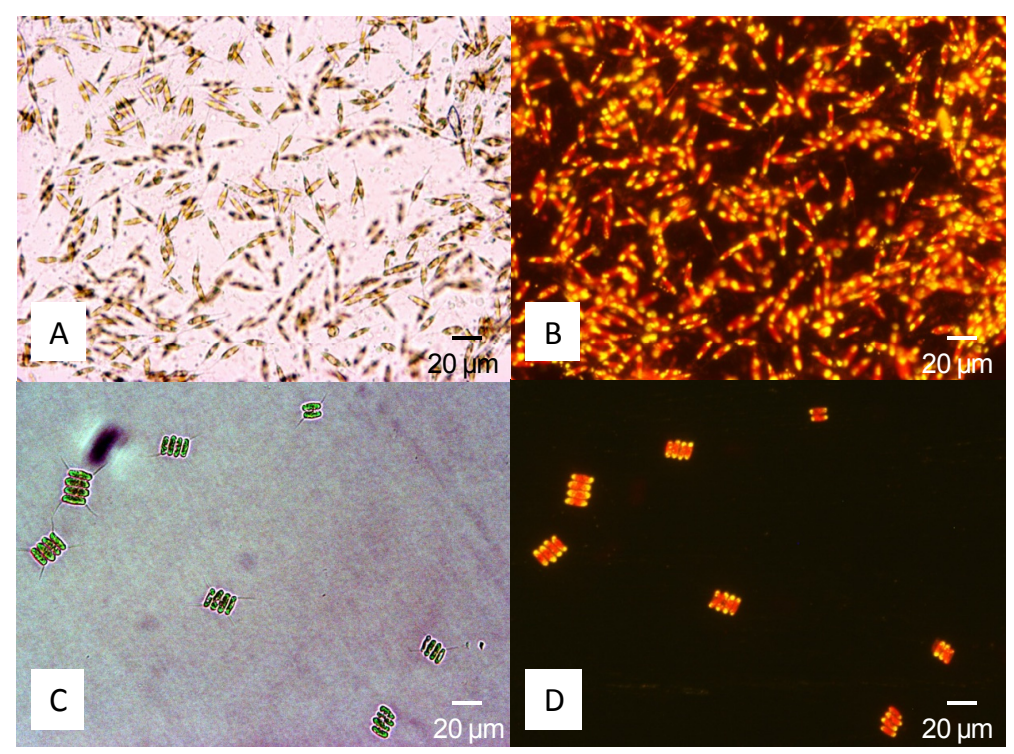

Although Nile red can be applied for rapid lipid screening, this method has not been successful in some particular microalgae species due to variables such as staining time, temperature, rigid cell walls, etc. [34]. Thus, Nile red dye concentrations applied for lipid staining are different for particular microalgae species. To improve staining efficiency some factors can be considered. For instance, 
microwaves applied for staining were first introduced by Leong and Milios and then improved by Chiu et al. in 1987 [34-36]. Microwave exposure time was optimized for processes of pretreatment and staining. Results of this research showed that microwave-assisted staining increased remarkably fluorescence intensity using a spectrofluorometer from 476 to 820 arbitrary units (a.u.) for Pseudochlorococcum sp. and from 662 to 869 a.u. for Chlorella zofingiensis after $50 \mathrm{~s}$ of microwave exposure in a pretreatment process and after $60 \mathrm{~s}$ of staining. Dimethyl sulfoxide (DMSO) has also been used for enhancing lipid staining effectiveness [33,34,37] and maybe used in low quantities instead of acetone as a solvent to allow viability of cells after staining. This means that Nile red staining can not only be used as a preliminary quantitative fluorometric assay for relative comparisons among closely-related strains, but potentially also for mutant screening and selection of high lipid-yielding strains.

\subsection{Cultivation and Biomass Production}

Microalgae strains with potentially high lipid content (e.g., as determined by Nile red staining) need to be cultured to increase biomass and directly compared to each other in larger cultivation systems to assess their potential as biodiesel feedstock. Initial tests of the most promising algae strains usually are carried out at laboratory-scale using culturing flasks and other vessels, such as hanging bags, under well-defined growth conditions. The test should follow a standard protocol over a certain growth period to allow direct comparisons between strains in terms of growth rate and lipid accumulation ("lipid productivity"). It should be noted though that a standard assay does not take into consideration the potential of certain microalgae under carefully optimized conditions. An example of this assay is the following that is routinely used by our laboratory to compare lipid productivity: Pure (but not axenic) algae strains are cultured in $\mathrm{F} / 2$ medium (fresh or seawater) until near stationary growth occurs (less than $20 \%$ growth in $24 \mathrm{~h}$ as determined by cell counts). An inoculum of $5 \mathrm{~mL}$ of this culture is then used to start growth in $20 \mathrm{~mL}$ fresh $\mathrm{F} / 2$ medium exactly at $2 \mathrm{~h}$ after the start of the light cycle. The culture is then grown and monitored by cell counting for 7 days after which medium is replaced with nutrient-free water. Nutrient starvation is conducted after that for another 2 days of cultivation to test the potential for rapid TAG accumulation. In addition, biomass is collected at the end of the experiment for lipid content analysis. This assay is useful for screening of growth and lipid producing capacity of microalgae, leading to selection of potentially useful strains.

The best candidate strains with potential for biodiesel production should then be used to optimize parameters for rapid growth, lipid induction, harvesting/dewatering and oil extraction. While most of these parameters are typically optimized under small-scale laboratory conditions, it seems advisable to move towards larger size outdoor cultivation conditions as soon as possible, as these are typically quite different. Parameters, such as salinity, nutrient composition, $\mathrm{pH}$ and cell density can be controlled to some extent, but other factors such as temperature, irradiation and the co-cultivation of other organisms are much harder to control under outdoor conditions.

In summary, it is advantageous to isolate and screen a large number of local microalgae strains and test these under mid-scale outdoor conditions as soon as possible to be close to conditions that maybe expected for large-scale cultivation. Figure 2 provides a step-by-step overview of how microalgae may be rapidly isolated and selected for larger scale biodiesel production. 


\subsection{Testing at Larger Scale}

At larger scale, two popular cultivation systems have been used for microalgal biomass and lipid production: open raceway ponds and closed photobioreactors. At present, open pond systems, especially large raceway ponds, are much more widely used, but bear the risk of attracting competing algae, grazers or viruses [38]. Although minimizing the cost of algae farming is one of highest priorities to achieve commercial algal biodiesel production, both systems require optimization of complex factors that satisfy high level production cultivation.

Figure 2. Suggested 5-step protocol for rapid selection of microalgae for biodiesel production. Step 1: Local sampling sites should be chosen where microalgae frequently undergo adverse conditions; Step 2: Dilution series in growth medium provide the simplest, most cost-effective and fastest method; Step 3: Nile red staining of near stationary cultures followed by visual inspection provides a simple and rapid screening for algae with high lipid accumulation ability; Step 4: A standardized growth assay in the laboratory can provide comparative data on lipid productivity; Step 5: Parameters can be directly optimized under outdoor conditions using mid-scale cultures as these are often very different to small-scale laboratory conditions.

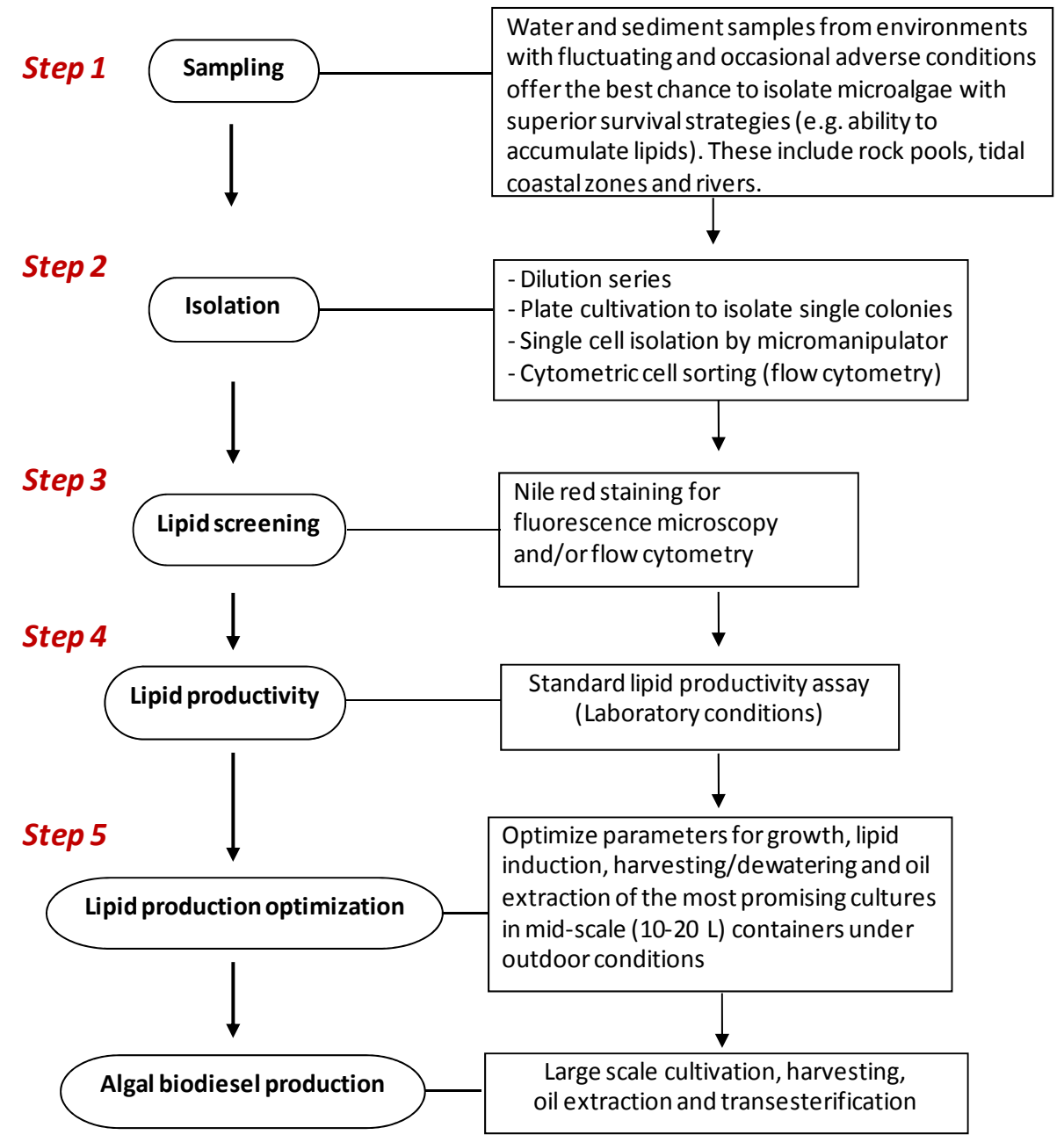


For example, these include irradiation, nutrients, temperature, dissolved $\mathrm{O}_{2}$ and $\mathrm{CO}_{2}$ contents, $\mathrm{pH}$, salinity, water quality, mixing efficiency and harvesting ability. Culturing and environmental conditions affect algae productivity, lipid yield and fatty acid compositions. For example, a pilot study showed that high growth rates and lipid accumulation of Chlorella sp. could be achieved primarily by increasing nitrogen concentrations and nitrogen starvation, respectively [39]. Similarly, growth of hydrocarbon-producing Botryococcus braunii was strongly dependent on light, temperature, salinity [40], nutrient quantity and composition [41]. Total lipid, carotene and chlorophyll contents of Navicula sp. increased with increasing salinity of the medium from 0.5 to $1.7 \mathrm{M} \mathrm{NaCl}$ [42]. In some cases, wastewater (e.g., municipal wastewater) can be used as a nutrient source of microalgae growth. Pulz suggested that productivity of $60-100 \mathrm{mg}$ dry weight $\mathrm{L}^{-1} \mathrm{~d}^{-1}$ or a biomass concentration of $1 \mathrm{~g} \mathrm{~L}^{-1}$ is achievable in open pond systems [43]. Table 2 lists some of the desirable traits for the selection process of microalgae with potential for biodiesel production.

Table 2. Checklist for desirable traits for microalgae selection with potential for biodiesel production and high-value byproducts.

\begin{tabular}{|l|l|}
\hline Steps & Desirable traits \\
\hline Screening & High oil \\
& High saturated fatty acids \\
& Low unsaturated fatty acids \\
& High omega 3 fatty acids \\
& Rapid and synchronized lipid production \\
& Radiation tolerance/pigment synthesis \\
& Antioxidants, sterols, carotenoids, astaxanthins and other pigments \\
& Low starch contents \\
& High protein contents \\
\hline Cultivation & Rapid growth \\
& Salinity/freshwater tolerance \\
& High/low temperature tolerance \\
& Reduced antennal pigments (for improved photosynthesis in bioreactor) \\
& Flagella properties/possession \\
& Sheering resistance \\
\hline Harvesting & Cell size and cell wall properties amenable for autoflocculation \\
& Sinking speed \\
& Foam fractionation properties \\
& Structure and cell wall properties \\
\hline Extraction & Cell wall properties amenable for oil extraction \\
& Lipid extraction efficiency \\
\hline
\end{tabular}

\section{Lipid Content in Microalgae}

Many microalgae are capable of accumulating a large amount of lipids in the cells [10]. On average, the lipid contents typically range from 10 to $30 \%$ of dry weight (Table 3 ). Depending on the specific algae species and their cultivation conditions, however, microalgal lipid production may range widely from 2 to $75 \%$ [2]. In some extreme cases, it can reach $70 \%-90 \%$ of dry weight [4,5]. For instance, the 
freshwater green alga Botryococcus braunii can produce oil (including hydrocarbons) up to $86 \%$ of its dry cell weight [44]. This species is being considered as a possible source for biodiesel production in the near future [4], but has the major disadvantage of slow growth rates and a low tolerance for contamination. As a result, lipid productivities (lipid production per area or volume) of other microalgae, such as Nannochloropsis, Chlorella, Tetraselmis and Pavlova sp. are typically much higher $[39,45]$. Lipid productivity can be dramatically increased by external application of stress factors and is considered a survival strategy for microalgae under adverse conditions. Most notably these include nutrient deprivation, exposure to chemicals, changes in salinity, temperature, $\mathrm{pH}$ and/or irradiation $[4,39,46]$. The composition of fatty acids-containing lipids differs widely among species, but, as mentioned above, generally includes structural unsaturated polar lipids, as well as neutral storage lipids, mostly in the form of TAG. Significant fatty acids used for biodiesel include saturated fatty acids and polyunsaturated fatty acids (PUFAs) containing 14-18 carbon molecules, such as C14:0, C16:0, C16:1, C18:0, C18:1, C18:2, C18:3 fatty acids [41]. According to European requirements for biodiesel standards, some fatty acids should be excluded because of undesirable properties. For instance, methyl linolenate and fatty acid methyl esters with more than four double bonds are limited to $12 \%$ due to oxidation properties [47].

Table 3. Examples of lipid contents in some microalgae species [4,48].

\begin{tabular}{|l|c|c|c|}
\hline Species & $\begin{array}{c}\text { Total lipids } \\
\text { (\% dry weight) }\end{array}$ & $\begin{array}{c}\text { PUFA } \\
\text { (\% total lipids) }\end{array}$ & $\begin{array}{c}\text { PUFA } \\
\text { (\% dry weight) }\end{array}$ \\
\hline Isochrysis galbana & 25.6 & 17 & 4.3 \\
Nanaochloropsis sp. & 5.6 & 2.8 & 0.2 \\
Chaetoceros calcitrans & 11.8 & 8.7 & 0.9 \\
Tetreselmis suecica & 2.5 & 20.9 & 0.2 \\
Skeletonema costatum & 9.7 & 5.1 & 0.5 \\
Phaeodactylum tricornutum & & 30 & 0.3 \\
Porphyridium cruentum & 1.5 & 17.1 & \\
Crypthecodinium cohnii & 20 & & \\
Botryococcus braunii & $25.0-75.0$ & & \\
Chlorella sp. & $10.0-48.0$ & & \\
\hline
\end{tabular}

It is expected that microalgae that offer a multiple product portfolio as part of a biorefinery, will be most applicable to large-scale commercial cultivation. In a microalgae screening process, besides fatty acids with properties relevant for biodiesel production, some high value products such as protein-rich biomass, omega-3 fatty acids, sterols, antioxidants, vitamins and pigments should also be taken into account. In particular, omega-3 fatty acids from microalgae have received significant attention as a high-value add product, as the current sources of fish oil are unsustainable due to depleting global fish stocks. A comparison of omega-3 fatty acid contents of different microalgae shows that these differ considerably between species (Table 4).

\section{Cultivation and Lipid Extraction Properties of Microalgae}

High lipid productivity is not the only factor that should be considered early during strain selection. Outdoor cultivation should determine whether the selected microalgae are robust enough to withstand 
variable local climatic conditions and whether they can dominate a culture. This is particularly important for open pond systems where other algae strains, grazers or viruses may easily contaminate the culture. For this purpose, many phycologists recommend the use of local dominant species, even if their lipid productivity may not be as high as other species [43].

Table 4. Examples of potential microalgae species for omega-3 production [48].

\begin{tabular}{|l|c|c|}
\hline Species & $\begin{array}{c}\text { Eicosapentaenoic acid (EPA) } \\
\text { (\% of total fatty acids) }\end{array}$ & $\begin{array}{c}\text { Docosahexaenoic acid (DHA) } \\
\text { (\% of total fatty acids) }\end{array}$ \\
\hline Isochrysis galbana & 0.9 & \\
Nannochloropsis sp. & 30.1 & \\
Chaetoceros calcitrans & 34 & \\
Tetraselmis suecica & 6.2 & 0.8 \\
Chaetoceros muelleri & 12.8 & 1.5 \\
Pavlova salina & 19.1 & 2.3 \\
Skeletonema costatum & 40.7 & 30 \\
Porphyridium cruentum & 30.7 & 7.1 \\
Crypthecodinium cohnii & & 0.6 \\
Chroomonas salina & 12.9 & \\
Chaetoceros constriccus & 18.8 & \\
Tetraselmis viridis & 6.7 & \\
\hline
\end{tabular}

Harvesting capability is another important feature of microalgae with biodiesel potential. Harvesting or dewatering can be best achieved through settling, flocculation or froth flotation [49,50]. For example, many microalgae settle under adverse conditions, and this can be tested under small scale conditions [51]. Lipid extraction efficiency from microalgae is dependent on residual water content after drying and in particular the structure of their cell wall. For example, Nannochloropsis sp. is regarded a highly productive microalga with strong potential for large-scale biodiesel production [43], but ideally requires pretreatment to open up the highly rigid cell walls for higher lipid extraction efficiency.

\section{Conclusions}

Development of biodiesel production from microalgae presents an important move to address the limitations posed by current first generation biodiesel crops. Microalgae, once developed for commercial biodiesel production, may offer many economical and environmental advantages. Current biodiesel production from microalgae is in the research phase, but is being developed to commercial scale in many countries. Finding promising microalgae for commercial cultivation is multi-facetted and challenging because particular microalgae strains have different requirements in terms of nutrients intake, environmental and culturing conditions and lipid extraction technology. However, diversity of lipid-producing microalgae species is one of the major advantages of this group of organisms that is likely to lead to selection of suitable algae crops to achieve algal biodiesel production in different regions. A combination of conventional and modern techniques is likely the most efficient route from isolation to large-scale cultivation (Figure 2). Careful initial analyses and far-sighted selection of 
microalgae with a view towards downstream processing and large-scale production with potential value-add products, is an important prerequisite to domesticate and develop algae crops for biodiesel production.

\section{Acknowledgements}

We wish to thank members of the Algae Biotechnology Laboratory at The University of Queensland for their valuable comments during writing of this article, and the Australian Research Council and the Australian Endeavour Award Program for financial support.

\section{References}

1. Richmond, A. Handbook of Microalgal Culture: Biotechnology and Applied Phycology; Blackwell Science Ltd.: Hudson County, NJ, USA, 2004.

2. Mata, T.M.; Martins, A.A.; Caetano, N.S. Microalgae for biodiesel production and other applications: A review. Renew. Sustain. Energy Rev. 2010, 14, 217-232.

3. CSIRO. Australian national algae culture collection. Available online: http://www.csiro.au/ Organisation-Structure/National-Facilities/Australian-National-Algae-Culture-Collection.aspx (accessed on 19 January 2012).

4. Chisti, Y. Biodiesel from microalgae. Biotechnol. Adv. 2007, 25, 294-306.

5. Li, Q.; Du, W.; Liu, D. Perspectives of microbial oils for biodiesel production. Appl. Microbiol. Biotechnol. 2008, 80, 749-756.

6. European Biodiesel Board. The EU biodiesel industry. Available online: http://www.ebb-eu.org/ stats.php (accessed on 18 January 2012).

7. Carriquiry, M. U.S. Bidiesel production: Recent developments and prospects. Iowa Agric. Rev. Online 2007, 13, 8-9.

8. TUSNBB. Production statistics. Available online: http://www.biodiesel.org/production/ production-statistics (accesssed on 18 January 2012).

9. Wang, B.; Li, Y.; Wu, N.; Lan, C.Q. $\mathrm{CO}_{2}$ bio-mitigation using microalgae. Appl. Microbiol. Biotechnol. 2008, 79, 707-718.

10. Sheehan, J.; Dunahay, T.; Benemann, J.; Roessler, P. A Look Back at the U.S. Department of Energy's Aquatic Species Program: Biodiesel from Algae; National Renewable Energy Laboratory: Golden, Colorado, USA, 1998.

11. Delucchi, M.A. A Lifecycle Emission Model (LEM): Lifecycle Emissions from Transportation Fuels; Motor Vehicles, Transportation Modes, Electricity Use, Heating and Cooking Fuels; Institute of Transport Studies, University of California: Davis, CA, USA, 2003.

12. Paulson, N.D.; Ginder, R.D. The Growth and Direction of Biodiesel Industry in the United States; Center for Agricultural and Rural Development: Iowa State University, IA, USA, 2007.

13. Laboratory, N.R.E. Biodiesel Handling and Use Guide; The U.S. Department of Energy: Golden, Colorado, USA, 2009.

14. Fukuda, H.; Kondo, A.; Noda, H. Biodiesel fuel production by transesterification of oils. J. Biosci. Bioeng. 2001, 92, 405-416. 
15. Bahadur, N.P.; Boocock, D.G.B.; Konar, S.K. Liquid hydrocarbons from catalytic pyrolysis of sewage sludge lipid and canola oil: Evaluation of fuel properties. Energy Fuels 1995, 9, 248-256.

16. Boateng, A.A.; Mullen, C.A.; Goldberg, N.; Hicks, K.B.; Jung, H.-J.G.; Lamb, J.F.S. Production of bio-oil from alfalfa stems by fluidized-Bed fast pyrolysis. Ind. Eng. Chem. Res. 2008, 47, 4115-4122.

17. Davey, H.M.; Kell, D.B. Flow cytometry and cell sorting of heterogeneous microbial populations: The importance of single-cell analyses. Microbiol. Rev. 1996, 60, 641-696.

18. Reckermann, M. Flow sorting in aquatic ecology. Sci. Mar. 2000, 64, 235-246.

19. Dinh, L.T.T.; Guo, Y.; Mannan, M.S. Sustainability evaluation of biodiesel production using multicriteria decision-making. Environ. Prog. Sustain. Energy 2009, 28, 38-46.

20. Rismani-Yazdi, H.; Haznedaroglu, B.Z.; Bibby, K.; Peccia, J. Transcriptome sequencing and annotation of the microalgae Dunaliella tertiolecta: Pathway description and gene discovery for production of next-generation biofuels. BMC Genomics 2011, 12, 148.

21. Tonon, T.; Harvey, D.; Qing, R.; Li, Y.; Larson, T.R.; Graham, I.A. Identification of a fatty acid $\triangle 11$-desaturase from the microalga Thalassiosira pseudonana. FEBS Lett. 2004, 563, 28-34.

22. Berard, A.; Dorigo, U.; Humbert, J.F.; Martin-Laurent, F. Microalgae community structure analysis based on 18S rDNA amplification from DNA extracted directly from soil as a potential soil bioindicator. Agronomie 2005, 25, 1-7.

23. Rasoul-Amini, S.; Ghasemi, Y.; Morowvat, M.H.; Mohagheghzadeh, A. PCR amplification of $18 \mathrm{~S}$ rRNA, single cell protein production and fatty acid evaluation of some naturally isolated microalgae. Food Chem. 2009, 116, 129-136.

24. Matsumoto, M.; Sugiyama, H.; Maeda, Y.; Sato, R.; Tanaka, T.; Matsunaga, T. Marine diatom, Navicula sp. strain JPCC DA0580 and marine green alga, Chlorella sp. strain NKG400014 as potential sources for biodiesel production. Appl. Biochem. Biotechnol. 2010, 161, 483-490.

25. Timmins, M.; Thomas-Hall, S.R.; Darling, A.; Zhang, E.; Hankamer, B.; Marx, U.C.; Schenk, P.M. Phylogenetic and molecular analysis of hydrogen-producing green algae. J. Exp. Bot. 2009, 60, 1691-1702.

26. Yu, Y.; Chen, B.; You, W. Identification of the alga known as Nannochloropsis Z-1 isolated from a prawn farm in Hainan, China as Chlorella. World J. Microbiol. Biotechnol. 2007, 23, 207-210.

27. Radakovits, R.; Jinkerson, R.E.; Darzins, A.; Posewitz, M.C. Genetic engineering of algae for enhanced biofuel production. Eukaryot. Cell 2010, 9, 486-501.

28. Schuhmann, H.; Lim, D.K.Y.; Schenk, P.M. Perspectives on metabolic engineering for increased lipid contents in microalgae. Biofuels 2012, 3, 71-86.

29. Radakovits, R.; Jinkerson, R.E.; Fuerstenberg, S.I.; Tae, H.; Settlage, R.E.; Boore, J.L.; Posewitz, M.C. Draft genome sequence and genetic transformation of the oleaginous alga Nannochloropis gaditana. Nat. Commun. 2012, 3, 686.

30. Bligh, E.G.; Dyer, W.J. A rapid method for total lipid extraction and purification. Can. J. Biochem. Phys. 1959, 37, 911-917.

31. Eltgroth, M.L.; Watwood, R.L.; Wolfe, G.V. Production and cellular localization of neutral long-chain lipids in the haptophyte algae Isochrysis galbana and Emiliania huxleyi. J. Phycol. 2005, 41, 1000-1009. 
32. Greenspan, P.; Mayer, E.P.; Fowler, S.D. Nile red-A selective fluorescent stain for intracellular lipid droplets. J. Cell Biol. 1985, 100, 965-973.

33. Chen, W.; Zhang, C.; Song, L.; Sommerfeld, M.; Hu, Q. A high throughput Nile red method for quantitative measurement of neutral lipids in microalgae. J. Microbiol. Methods 2009, 77, 41-47.

34. Chen, W.; Sommerfeld, M.; Hu, Q. Microwave-assisted Nile red method for in vivo quantification of neutral lipids in microalgae. Bioresour. Technol. 2011, 102, 135-141.

35. Chiu, K.Y.; Chan, K.W. Rapid immunofluorescence staining of human renal biopsy speciments using microwave irradiation. J. Clin. Pathol. 1987, 40, 689-692.

36. Muñoz, T.E.; Giberson, R.T.; Demaree, R.; Day, J.R. Microwave-assisted immunostaining: A new approach yields fast and consistent results. J. Neurosci. Methods 2004, 137, 133-139.

37. Spaulding, B.W. A Nile red staining method for the fluorescence detection of lipid in algae utilizing a FlowCAM: Biofuels digest. Available online: http://www.biofuelsdigest.com/ bdigest/2010/05/05/a-nile-red-staining-method-for-the-fluorescence-detection-of-lipid-in-algae-uti lizing-a-flowcam/ (accessed on 31 January 2012).

38. Schenk, P.; Thomas-Hall, S.; Stephens, E.; Marx, U.; Mussgnug, J.; Posten, C.; Kruse, O.; Hankamer, B. Second generation biofuels: High-efficiency microalgae for biodiesel production. Bioenerg. Res. 2008, 1, 20-43.

39. Rodolfi, L.; Chini Zittelli, G.; Bassi, N.; Padovani, G.; Biondi, N.; Bonini, G.; Tredici, M.R. Microalgae for oil: Strain selection, induction of lipid synthesis and outdoor mass cultivation in a low-cost photobioreactor. Biotechnol. Bioeng. 2009, 102, 100-112.

40. Li, Y.; Qin, J.G. Comparison of growth and lipid content in three Botryococcus braunii strains. J. Appl. Phycol. 2005, 17, 6.

41. Thomas, W.H.; Tornabene, T.G.; Weissman, J. Screening for Lipid Yielding Microalgae: Activities for 1983; Solar Energy Research Institute: Golden, Colorado, USA, 1984.

42. Al-Hasan, R.; Ali, A.; Ka'wash, H.; Radwan, S. Effect of salinity on the lipid and fatty acid composition of the halophyte Navicula sp.: Potential in mariculture. J. Appl. Phycol. 1990, 2, 215-222.

43. Pulz, O.P. Photobioreactors: Production systems for phototrophic microorganisms. Appl. Microbiol. Biotechnol. 2001, 57, 287-293.

44. Brown, A.C.; Knights, B.A.; Conway, E. Hydrocarbon content and its relationship to physiological state in the green alga Botryococcus braunii. Phytochemistry 1969, 8, 5.

45. Huerlimann, R.; de Nys, R.; Heimann, K. Growth, lipid content, productivity, and fatty acid composition of tropical microalgae for scale-up production. Biotechnol. Bioeng. 2010, 107, $245-257$.

46. Miao, X.; Wu, Q. Biodiesel production from heterotrophic microalgal oil. Bioresour. Technol. 2006, 97, 841-846.

47. Knothe, G. Analyzing biodiesel: Standards and other methods. J. Am. Oil Chem. Soc. 2006, 83, 823-833.

48. Yan, L.; Schenk, P.M. Selection of Cultured Microalgae for Producing Omega-3 Bio-Lipid Oil; Report for Queensland Sea Scallop Trading Pty Ltd.; The University of Queensland: Queensland, Austrilia, 2011; p. 36. 
49. Scholz, M.; Hoshino, T.; Johnson, D.; Riley, M.R.; Cuello, J. Flocculation of wall-deficient cells of Chlamydomonas reinhardtii mutant cw15 by calcium and methanol. Biomass Bioenerg. 2011, 35, 4835-4840.

50. Christenson, L.; Sims, R. Production and harvesting of microalgae for wastewater treatment, biofuels, and bioproducts. Biotechnol. Adv. 2011, 29, 686-702.

51. Park, J.B.K.; Craggs, R.J.; Shilton, A.N. Recycling algae to improve species control and harvest efficiency from a high rate algal pond. Water Res. 2011, 45, 6637-6649.

(C) 2012 by the authors; licensee MDPI, Basel, Switzerland. This article is an open access article distributed under the terms and conditions of the Creative Commons Attribution license (http://creativecommons.org/licenses/by/3.0/). 